\title{
Precise humidity control materials for autonomous regulation of indoor moisture
}

\author{
Qin, Menghao; Hou, Pumin; Wu, Zhimin; Wang, Juntao
}

Published in:

Building and Environment

Link to article, DOI:

10.1016/j.buildenv.2019.106581

Publication date:

2020

Document Version

Peer reviewed version

Link back to DTU Orbit

Citation (APA):

Qin, M., Hou, P., Wu, Z., \& Wang, J. (2020). Precise humidity control materials for autonomous regulation of indoor moisture. Building and Environment, 169, [106581]. https://doi.org/10.1016/j.buildenv.2019.106581

\section{General rights}

Copyright and moral rights for the publications made accessible in the public portal are retained by the authors and/or other copyright owners and it is a condition of accessing publications that users recognise and abide by the legal requirements associated with these rights.

- Users may download and print one copy of any publication from the public portal for the purpose of private study or research.

- You may not further distribute the material or use it for any profit-making activity or commercial gain

- You may freely distribute the URL identifying the publication in the public portal

If you believe that this document breaches copyright please contact us providing details, and we will remove access to the work immediately and investigate your claim. 


\section{Journal Pre-proof}

Precise humidity control materials for autonomous regulation of indoor moisture

Menghao Qin, Pumin Hou, Zhimin Wu, Juntao Wang

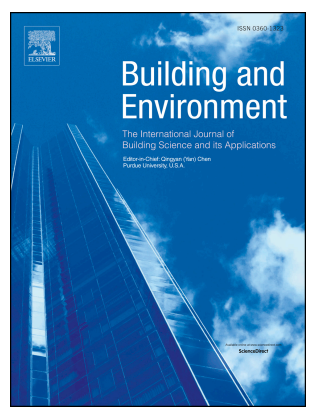

PII: $\quad$ S0360-1323(19)30793-0

DOI: $\quad$ https://doi.org/10.1016/j.buildenv.2019.106581

Reference: BAE 106581

To appear in: Building and Environment

Received Date: 1 July 2019

Revised Date: 23 November 2019

Accepted Date: 2 December 2019

Please cite this article as: Qin M, Hou P, Wu Z, Wang J, Precise humidity control materials for autonomous regulation of indoor moisture Building and Environment, https://doi.org/10.1016/ j.buildenv.2019.106581.

This is a PDF file of an article that has undergone enhancements after acceptance, such as the addition of a cover page and metadata, and formatting for readability, but it is not yet the definitive version of record. This version will undergo additional copyediting, typesetting and review before it is published in its final form, but we are providing this version to give early visibility of the article. Please note that, during the production process, errors may be discovered which could affect the content, and all legal disclaimers that apply to the journal pertain.

(C) 2019 Elsevier Ltd. All rights reserved. 


\title{
Precise humidity control materials for autonomous regulation
}

\section{of indoor moisture}

\author{
Menghao Qin ${ }^{1, *}$, Pumin $\mathrm{Hou}^{1}$, Zhimin $\mathrm{Wu}^{2}$, Juntao Wang ${ }^{3}$ \\ ${ }^{1}$ Department of Civil Engineering, Technical University of Denmark, Lyngby, Denmark \\ ${ }^{2}$ School of Architecture and Urban Planning, Nanjing University, Nanjing, China \\ ${ }^{3}$ Department of Chemistry, Technical University of Denmark, Lyngby, Denmark \\ *Corresponding email: menqin@byg.dtu.dk (Prof. M. Qin)
}

\begin{abstract}
Indoor relative humidity is an important parameter to determine indoor air quality, occupants' thermal comfort and building energy consumption. As recommended by ASHRAE, the appropriate indoor relative humidity range for a healthy and comfortable indoor environment is between $40 \%$ and $65 \% \mathrm{RH}$. In order to meet the requirements, the most commonly used method is mechanical dehumidification/humidification system by using electricity. However, this approach is energy consuming. In this paper, a novel precise
\end{abstract} humidity control material (PHCM) based on Metal-Organic Frameworks (MOFs) is synthesized and its application in built environment is investigated. This material has an S-shape isotherm, high porosity and very high water vapor uptake of $1.62 \mathrm{~g} / \mathrm{g}$ at $80 \% \mathrm{RH}$. It can rapidly adsorb moisture as the indoor relative humidity exceeds $60 \%$, and release moisture as relative humidity drops below $45 \%$. Unlike the conventional desiccants, e.g. zeolites, silica gel etc., MOF-PHCM can autonomously control indoor relative humidity within the desired comfort range at room temperature. Hygrothermal properties of the new material are measured. Numerical simulations have been carried out to study the effect of MOF-PHCM on indoor hygrothermal conditions and building energy consumption in five different climates worldwide (i.e. hot desert, semi-arid, Mediterranean, temperate, and humid subtropical). The results show that MOF-PHCM can effectively control indoor relative 
humidity fluctuations and reduce building energy consumption in most climates without any additional energy input. MOF-PHCM can be easily regenerated by either night ventilation (e.g. in hot desert, semi-arid, Mediterranean climates) or heating system powered by low-grade energy (e.g. in humid climates).

Keywords Precise humidity control material; MOFs; Indoor Relative humidity; Building energy saving

\section{Introduction}

Latent cooling load accounts for around one third of the total load of air-conditioning, and its proportion is even higher in some subtropical and tropical areas [1]. In order to maintain indoor comfort and to prevent microorganism growth, the American Society of Heating, Refrigerating, and Air-Conditioning Engineers (ASHRAE) recommends that indoor relative humidity should be maintained between $40 \%$ and $65 \%$, which is the desired comfort relative humidity range for human being. In the conventional air-conditioning system, air is cooled and dehumidified simultaneously. The latent cooling load is removed by the refrigeration dehumidification process. Air is cooled to the dew point first, and then re-heated to the set-point for indoor environment, which results in wasting a lot of energy [2]. Desiccants help the system to independently control both temperature and humidity and thus contribute to the reduction of the energy used $[3,4]$. Silica gels and zeolites are the most commonly used solid desiccants, but they are not very efficient for dehumidification owing to their high regeneration temperature, long cycling time and the fact that a larger part of their water vapor sorption occurs outside the desired comfort relative humidity range or the operating vapor pressure windows (i.e. between $40 \%$ and $65 \%$ RH) [5]. Dehumidification by liquid sorbents uses less electrical energy than refrigeration, but the relevant technology has distinct drawbacks for commercialization, e.g. the system is complex and bulky, and has corrosion 
problems $[6,7]$.

The ideal materials for autonomous regulation of indoor relative humidity should meet the following criteria:

(1) The material should have an IUPAC-type V [8] S-shape isotherm and exhibit a steep uptake isotherm at a specific relative humidity depending on the targeted application. For indoor humidity control for thermal comfort, the adsorption isotherm must have a steep rise around $65 \% \mathrm{RH}$, and the desorption isotherm must have a steep decrease around 40\% RH (see Fig. 1);

(2) High water vapor uptake within the operating vapor pressure window;

(3) Low regeneration temperature and high reproducible cycling performance;

(4) High hygrothermal stability, non-toxicity and non-corrosion.

Solid porous material that meets all above four criteria is named as Precise Humidity Control

\section{Material (PHCM).}

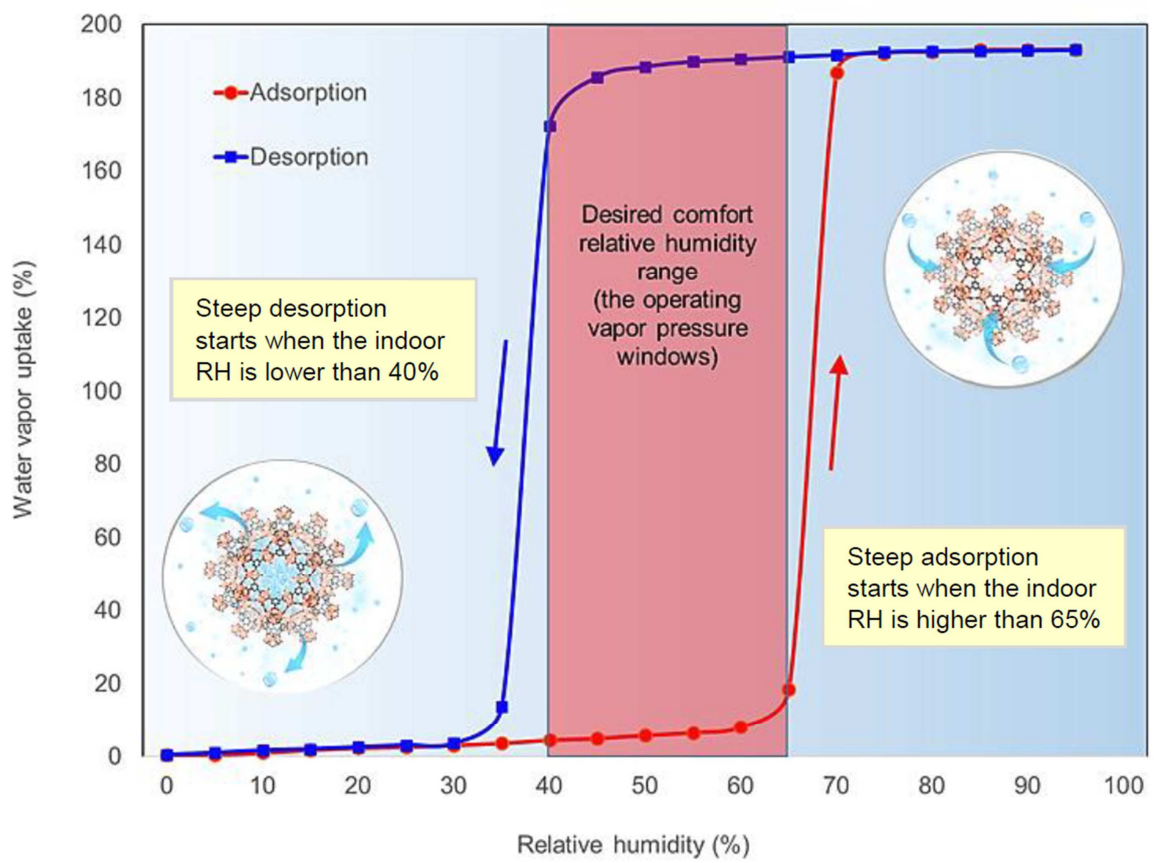

Figure 1. Working principle of the ideal PHCM for autonomous indoor humidity control 
Many studies have been carried out to investigate existing solid desiccants that exhibit a water vapor sorption isotherm with a sigmoidal or S-shape $[9,10]$. However, studies show that almost no traditional or conventional porous sorbent can meet all of the four above criteria. Most conventional porous materials have a limited water vapor uptake ability at room conditions, and are not able to autonomously control the indoor humidity level within a small range precisely. Therefore, developing novel desiccants with large water vapor uptake and precise humidity control ability is needed.

Metal-organic frameworks (MOFs) are an emerging class of porous materials [11]. Most MOFs can exhibit very high surface areas and large adsorption capacity for gas [12]. Due to their structural and functional tunability, MOFs have become one of the most fascinating classes of materials for both scientists and engineers [12, 13, 14]. MOFs can be used for gas storage, purification, catalysis, sensor and drug delivery, etc. [12]. Recent studies show that MOFs are also promising sorbents for water vapor $[6,13,14]$. The diverse choice of linkers and secondary building blocks (SBU) facilitate the modulation of the hydrophilicity and sorption kinetics [15-18]. The carboxylate-based MOFs show remarkable uptake for water vapor and require lower regeneration temperatures for the desorption compared to conventional sorbents [6, 14]. Some MOFs, such as Al-fumarate [19] and CAU-10-H [20], PIZOF-2 [21], 33R [22], Cr-MIL-101 [23], Cr-MIL-101-NH 2 [24], Cr-MIL-101-NO 2 [25], Y-shp-MOF5 [26], MIL-100(Fe) [27] and Al-MIL-53-OH [28] show good water vapor adsorption properties for humidity control, and have different operating pressure windows in a general range of $20 \%$ to $80 \%$ relative humidity. However, to the best of our knowledge, only very few of MOF materials can meet the all criteria for PHCM. In addition, most previous studies about MOFs are from chemistry discipline, and mainly focus on the 
synthesis and characterization of new materials. Detailed investigations of the effect of MOFs on indoor hygrothermal conditions and building energy performance have not been reported.

This paper aims to synthesis a MOF-based precise humidity control material (PHCM) that can realize the autonomous regulation of indoor relative humidity, and study the performance of the new MOF-PHCM for the indoor humidity control in different climates. First, the synthesis procedure and hygrothermal characterizations of the new MOF-PHCM will be reported, and the moisture buffer value (MBV) of the material will also be measured. Secondly, the energy saving potential by using MOF-PHCM in different climates will be discussed.

\section{Synthesis and characterization}

\subsection{Synthesis of MOF based PHCM}

The preparation was carried out at the Department of Chemistry at DTU. Typically, MOFs are constructed from linking metal centers or clusters with organic linkers via relatively strong coordination bonds. The detailed processes of the MOF-PHCM are presented as follows. $0.3 \mathrm{ml} 0.1 \mathrm{M} \mathrm{FeCl}_{3} \cdot 6 \mathrm{H}_{2} \mathrm{O}$ in Dimethylformamide (DMF) $(0.03 \mathrm{mmol})$ was added to a $23 \mathrm{ml}$ glass scintillation vial containing 3,3",5,5"-tetrakis (4-carboxyphenyl)-p-terphenyl $\left(\mathrm{H}_{4} \mathrm{TCPT}\right)\left(\mathrm{H}_{4} \mathrm{Ll}\right)$ (The numbers 3,3" and 5,5" refer to the positions on the terphenyl ring where the tetrakis (4-carboxyphenyl) is attached [29].) (0.01 mmol), $1 \mathrm{ml} \mathrm{DMF,} 1 \mathrm{ml} \mathrm{CH}{ }_{3} \mathrm{CN}$, and $1.5 \mathrm{ml}$ nitric acid (3.5 $\mathrm{M}$ in DMF). The vial was sealed and placed into a preheated oven at $115{ }^{0} \mathrm{C}$ for 3 days. Pure orange cube-shaped crystals were obtained and washed with $\mathrm{CH}_{3} \mathrm{CN}$ and air-dried [29]. The molecular formula of the orange crystals is $\left[\mathrm{Fe}_{3}\left(\mu_{3}-\mathrm{O}\right)\left(\mathrm{H}_{2} \mathrm{O}\right)\left(\mathrm{O}_{2} \mathrm{C}^{-}\right)_{6}\right]$. Since the orange crystals are not very water stable, the following steps were carried out to replace $\mathrm{Fe}^{3+}$ with other more water stable ions, for example, 
zirconium [21], aluminum [29] and chromium [23, 24] etc. The DVS tests show that Cr-MOF has the largest water vapor uptake among other MOFs. Therefore, chromium is selected to replace $\mathrm{Fe}^{3+}$ for the second step of the synthesis. $25 \mathrm{mg}$ of orange crystals was added in a 20 ml scintillation vial. In another vial, $150 \mathrm{ml}$ of $\mathrm{CrCl}_{2}$ was dissolved in $3 \mathrm{ml}$ of DMF. The solution was then added to the first vial. The vial was capped and incubated at $115{ }^{\circ} \mathrm{C}$ for 24 hours, and then was cool to room temperature. Pure green crystals were obtained and washed with DMF several times (see Fig. 2). The molecular formula of the green crystals is $\left[\mathrm{Cr}_{3}\left(\mu_{3}-\mathrm{O}\right)\left(\mathrm{H}_{2} \mathrm{O}\right)\left(\mathrm{O}_{2} \mathrm{C}^{-}\right)_{6}\right]$

Finally, the green crystals were coated into macroscopic layers on a metal surface. The concept of coating allows the MOFs to rapidly dissipate or absorb heat under isothermal conditions via a heat exchanger, which guarantee the desired sorption performance. The coating process used a water-borne binder of silica sol [6] (an aqueous silicic acid solution with water-insoluble silicon dioxide in colloid distribution), enabling the MOF layer to retain its original water vapor sorption features and capacity.

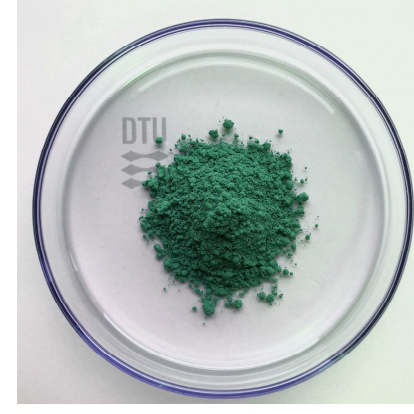

(a)

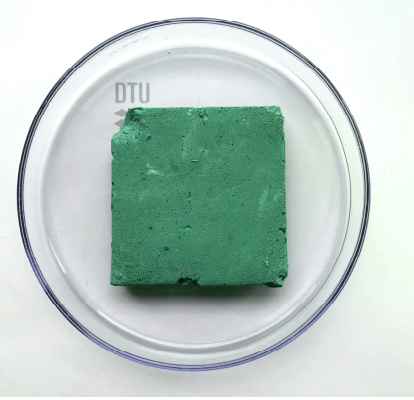

(b)
Figure 2. (a) MOF-PHCM powder, (b) MOF-PHCM in the form of a brick

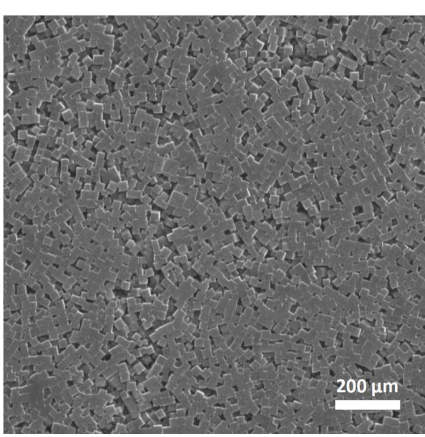

Figure 3. SEM image of MOF-PHCM crystals

\subsection{Characterization}

\subsubsection{Morphology}


Scanning electronic microscope (SEM) has been used to analyze the geometry of the new crystal. The images were taken by an FEI Quanta 200 ESEM FEG microscope equipped with an energy-dispersive X-ray (EDS) spectrometer. The SEM image is shown in Fig. 3. The size of single cubic crystal is around $25 \mu \mathrm{m}$. The average pore size is around $2 \mathrm{~nm}$.

\subsubsection{Water Vapor Sorption Experiments}

The water vapor sorption isotherm is one of the most important hygric properties of a porous material. The water vapor isotherms of the MOF-PHCM were measured by a DVS (Dynamic vapor sorption) instrument (Surface Measurement Systems DVS Adventure). The sample was first dried in DVS by the airflow with the temperature of $23 \square$ and $\mathrm{RH}$ of $0 \%$ until weight did not change. Then the RH of the airflow increases from $0 \%$ to $100 \%$. DVS will automatically record the weight of the sample when the weight of the sample retains constant at each RH step. The test results are shown in Fig. 4. The temperature during the measurements remains at $23 \square$. The mass of sample used for the DVS test is around $30 \mathrm{mg}$.

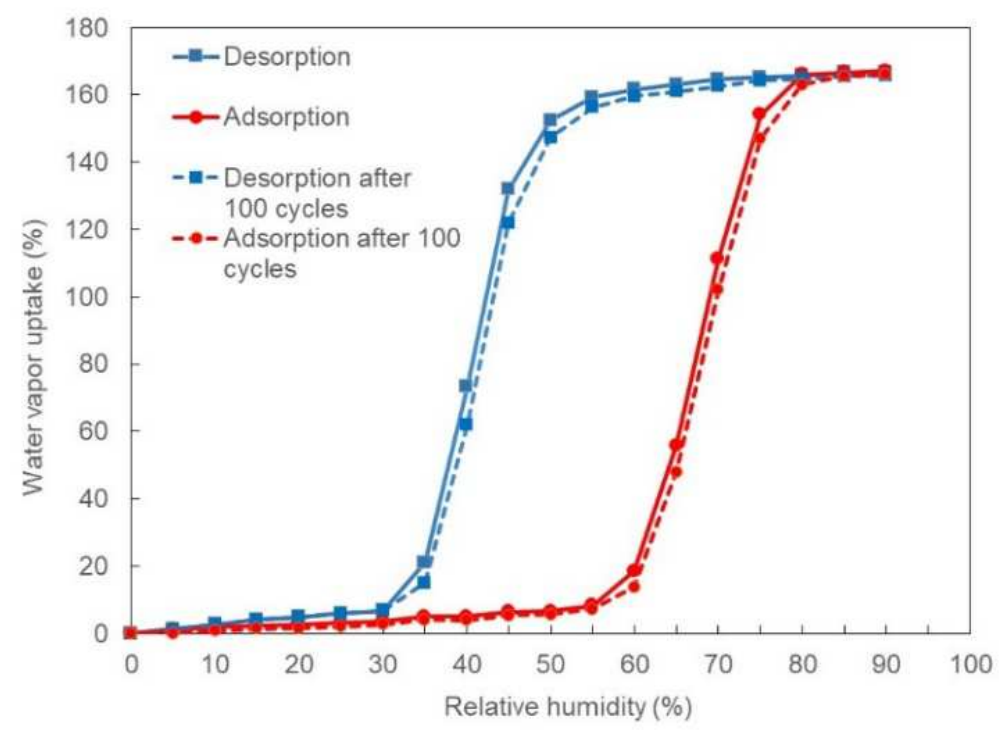

Figure 4. Water vapor sorption isotherms of MOF-PHCM

The steep adsorption occurs at $60 \% \mathrm{RH}$ and steep desorption occurs around $45 \% \mathrm{RH}$, 
respectively. Saturation approaches when the relative humidity reaches $80 \%$. The water vapor uptake of MOF-PHCM at $80 \% \mathrm{RH}$ is $1.62 \mathrm{~g} / \mathrm{g}$, which is much higher than most conventional sorbents and many MOFs [21]. Adsorption occurs in the inter-particulate voids. For the desorption curve, a visible hysteresis occurs. The water vapor isotherms show that the new MOF-PHCM meets the first and second criteria of the ideal PHCM for autonomous indoor humidity control. Fig. 4 also shows the water vapor isotherms of the material after 100 cycles. We can see there are only very minor changes to the isotherms, which means the adsorption and desorption of MOF-PHCM always take place in that specific way.

\subsubsection{Moisture Buffer Value (MBV)}

The moisture buffering through adsorption and desorption of the hygroscopic surface materials of building envelopes and furnishing (e.g. wood furniture, curtains, carpet, textiles etc. ) has an important effect on indoor hygrothermal conditions and energy performance of buildings [14, 30-32]. Hygroscopic surface materials can uptake moisture from the air when its relative humidity increases and release moisture to the air when its relative humidity falls.

In order to evaluate the moisture buffer capacity of different hygroscopic materials, Rode et al. [33] proposed the concept of moisture buffer value (MBV), which indicates the amount of moisture uptake/release by a material when it is exposed to diurnal relative humidity variations between two given values. According to the test protocol proposed in NORDTEST [33], the MBV is a direct measurement of the amount of water vapor absorbed or desorbed by a hygroscopic material when it is exposed to a square wave in daily cycles (for example, 8 hours of high relative humidity at $75 \%$ followed by 16 hours of low relative humidity at $33 \%$ ). Recently, Qin et al. [30] have improved the MBV theory and test methods.

The moisture buffer value (MBV) of the MOF-PHCM was measured according to the classic 
MBV test method proposed by NORDTEST. First, the sample $(27 \mathrm{~mm} \times 27 \mathrm{~mm} \times 20 \mathrm{~mm})$ was dried in an oven for 10 hours at $60 \square$. The thickness of the sample is larger than the penetration depth of the material, which is about $1.5 \mathrm{~cm}$ for MOF-PHCM in this research. Then the sample was sealed in a glass container in the climate chamber until the temperature of the samples dropped to the chamber temperature, which was $23 \square$. The measurement was conducted in a climate chamber. The temperature inside the chamber is $23 \square$. The external ambient temperature is between $20 \sim 25 \square$. The temperature and humidity sensors measure the temporal temperature and relative humidity, and the signal is sent back to a PID regulator and computer. Saturated air and dry air can be mixed in different proportion controlled by the PID regulator to maintain a stable humidity in the chamber. The temperature and humidity inside the climate chamber are uniform as a small axial fan is installed to make the inside air well mixed. The relative humidity inside the chamber was set as $75 \%$ for 8 hours and $33 \%$ for 16 hours in one period of time. The air humidity was switched swiftly.

The MOF sample was placed inside the climate chamber, and only the upper surface of the sample was exposed to the air in the chamber. The rest five surfaces were sealed to avoid moisture transport. The weight of MOF sample was measured and logged automatically by the balance every minute. The measurement was performed in several cycles to get a relatively constant MBV of the material. 


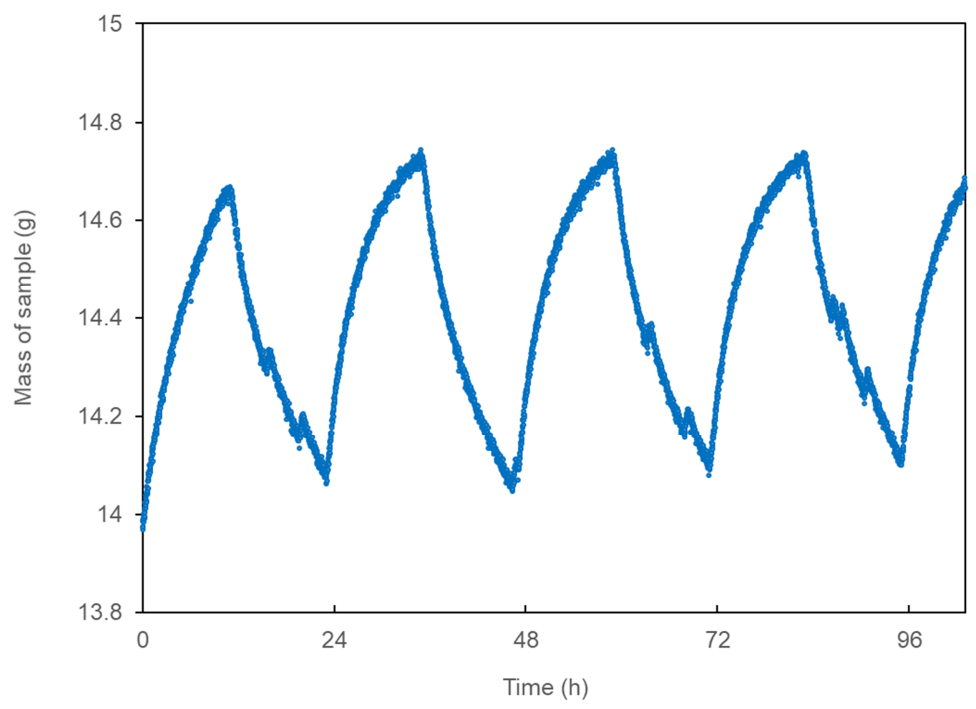

Figure 5. Mass variation during the MBV test

The mass variation during the MBV test is presented in Fig. 5. The test results show that the MBV of MOF-PHCM is $20.50 \mathrm{~g} \cdot \mathrm{m}^{-2} \cdot \mathrm{RH}^{-1}$ at 8 hours in the experimental conditions, which is almost 45 times higher than that of laminated wood and 36 times higher than gypsum [33]. The MBV test results indicate that the new MOF-PHCM has an exceptional performance of moisture buffering capacity within the hygroscopic range. Its MBV value is one magnitude higher than that of traditional/conventional building materials, and also much higher than other MOF desiccants, for example, MOF-100(Fe) [14]. MOF-PHCM has a great potential to be an ideal moisture sorbent for indoor humidity control. The MBVs of some traditional building materials and conventional materials are listed in the same table for comparison.

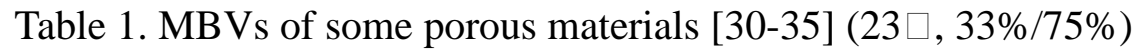

\begin{tabular}{lc}
\hline \multicolumn{1}{c}{ Material } & $\mathrm{MBV}\left(\mathrm{g} \cdot \mathrm{m}^{-2} \cdot \mathrm{RH}^{-1}\right)$ \\
\hline MOF-PHCM & 20.50 \\
MOF-100(Fe) & 7.40 \\
Spruce boards & 1.22 \\
Cellular concrete & 1.05
\end{tabular}




$\begin{array}{ll}\text { Brich panels } & 0.91 \\ \text { Vesuvianite } & 0.79 \\ \text { Gypsum } & 0.57 \\ \text { Sepiolite } & 0.54 \\ \text { Laminated Wood } & 0.46 \\ \text { Concrete } & 0.42 \\ \text { Brick } & 0.39\end{array}$

In addition, the vapor transfer coefficient of the new material was measured by the traditional cup method (see Appendix A for more details). It is $1.26 \times 10^{-7} \mathrm{~kg} \mathrm{~m}^{-1} \mathrm{~s}^{-1}$.

\section{Indoor hygrothermal simulation}

Both the moisture sorption isotherms and the MBV test show that the MOF based PHCM has an extraordinary moisture buffering capacity, which makes it very promising for indoor passive moisture control. Numerical simulations will be carried out to study the effect of MOF-PHCM on indoor humidity condition and building energy consumptions. The energy saving potential of applying MOF-PHCM in built environment in different climates will be investigated in this section.

\subsection{Indoor latent load model}

In order to investigate the buffering effect of MOF-PHCM on indoor environment, a simplified latent load model was developed. The model mainly focuses on the moisture balance/transfer in buildings because hygroscopic materials only affect the indoor moisture variation and their effect on indoor temperature can be neglected [36-38]. Generally, the indoor moisture conditions are mainly affected by the following factors: internal sources/sinks, moisture adsorption/desorption of internal hygroscopic materials, mechanical 
ventilation and infiltration, moisture diffusion through building envelopes, and heating and cooling systems. Vapor diffusion through building walls are not take into account in the current model since well-insulated modern buildings are normally equipped with vapor barrier, and are almost water impenetrable. There is no heating and cooling systems in the model. The indoor air is assumed to be well mixed, so the humidity at the ventilation exhaust is the same as the indoor humidity. The humidity of outside air varies with time depending on the outdoor weather condition. The variation rate of the indoor humidity ratio can be expressed as:

$m_{\text {in }} \frac{d c_{\text {in }}}{d t}=m_{v e n}\left(c_{\text {out }}(t)-c_{\text {in }}\right)+M_{\mathrm{PHCM}} V_{\mathrm{r}}+M_{\mathrm{g}} V_{\mathrm{r}}$

Where, $m_{\text {in }}$ is the mass of indoor air, $\mathrm{kg} ; m_{\mathrm{ven}}$ is mass of ventilation air, $\mathrm{kg}$; $c_{\text {out }}$ is the humidity ratio of outdoor air, $\mathrm{kg} \cdot \mathrm{kg}_{\mathrm{air}}{ }^{-1} ; c_{\mathrm{in}}$ is the humidity ratio of indoor air, $\mathrm{kg} \cdot \mathrm{kg}_{\mathrm{air}}{ }^{-1} ; V_{\mathrm{r}}$ is the room volume, $\mathrm{m}^{3} ; t$ is the time, $\mathrm{s} ; M_{\mathrm{g}}$ is the vapor generation rate, $\mathrm{kg} \cdot \mathrm{m}^{-3} \cdot \mathrm{s}^{-1} ; M_{\mathrm{PHCM}}$ is the absorption/desorption rate by MOF-PHCM multiplies the surface area of material and divides by the room volume, $\mathrm{kg} \cdot \mathrm{m}^{-3} \cdot \mathrm{s}^{-1}$, which can be calculated from the MBV theory [33].

By solving the differential equation (1), the indoor humidity ratio can be expressed as follows:

$c_{\text {in }}=e^{-\frac{m_{\mathrm{Ven}}}{m_{\text {in }}} t}\left(\frac{m_{\text {ven }}}{m_{\text {in }}} \int c_{\mathrm{out}}(t) e^{\frac{m_{\mathrm{ven}}}{m_{\text {in }}} t} d t+c_{\mathrm{in}}(0)-\frac{\left(M_{\mathrm{g}}+M_{\mathrm{MOF}}\right) V_{\mathrm{r}}}{m_{\mathrm{ven}}}\right)+\frac{\left(M_{\mathrm{g}}+M_{\mathrm{MOF}}\right) V_{\mathrm{r}}}{m_{\text {ven }}}$

Where, $c_{\text {in }}(0)$ is the initial humidity ratio of indoor air.

The time-dependent indoor air humidity can be calculated by Eq. (2), and the influence with and without the moisture buffering of MOF-PHCM can be evaluated. Then the latent load removed by MOF-PHCM can be derived by comparing the moisture fluctuation with and without MOF-PHCM. 
$Q_{1}=r_{0} m_{\mathrm{r}} \int_{t_{1}}^{t_{2}}\left(c_{\mathrm{rno}}-c_{\mathrm{rPHCM}}\right) d t$

Where, $Q_{1}$ is the latent load removed by MOF-PHCM, $\mathrm{kW} ; r_{0}$ is the latent heat of vaporization, $\mathrm{kJ} \cdot \mathrm{kg}^{-1} ; t_{1}$ and $t_{2}$ are the start and end time of occupied period, $\mathrm{s} ; c_{\mathrm{rno}}$ is the indoor air humidity ratio without MOF-PHCM, $\mathrm{kg} \cdot \mathrm{kg}_{\mathrm{air}}{ }^{-1} ; c_{\mathrm{rPHCM}}$ is the indoor air humidity ratio with MOF-PHCM, $\mathrm{kg} \cdot \mathrm{kg}_{\mathrm{air}}{ }^{-1}$. If the indoor air humidity level with MOF-PHCM drops below the lower limit of the comfort zone (i.e. $40 \% \mathrm{RH}$ in this research), $c_{\mathrm{rPHCM}}$ equals to the humidity ratio corresponding to the set-point condition.

\subsection{Model validation}

The International Energy Agency (IEA) Annex 41 project [39] has published a series of experimental tests for the validation of moisture buffer models. The experimental tests were carried out in Frauhofer Institut Fur Bauphysik, Germany. The volume of the test room is approx. $50 \mathrm{~m}^{3}$, and the total surface of the room is approx. $67 \mathrm{~m}^{2}$. All walls and ceiling surfaces of the test room were initially covered with aluminum foil to prevent the moisture sorption. A PVC covering was installed in order to avoid moisture flow to or from the ground. During the test, $50 \mathrm{~m}^{2}$ of uncoated gypsum boards were attached on top of the walls with aluminum foil inside. The moisture buffering effect of the gypsum boards were measured.

The rooms were equipped with calibrated heating, ventilation and moisture production systems. The indoor air temperature of the test room was held at $20{ }^{\circ} \mathrm{C}$. The tests were performed with a constant air change rate $(\mathrm{ACH})$ of $0.66 \mathrm{~h}^{-1}$. The solar radiation through the windows were ignored. The moisture production in the test room corresponds to a normal four-person household. The total moisture production is $2.4 \mathrm{~kg} \mathrm{~d}^{-1}$. A basic moisture 
production rate of $0.025 \mathrm{~kg} \mathrm{~h}^{-1}$ was assumed with peaks in the morning and in the evening (0.4 $\mathrm{kg} \mathrm{h}^{-1}$ from 6:00 to 8:00 a.m. and $0.2 \mathrm{~kg} \mathrm{~h}^{-1}$ from 16:00 to 22:00 p.m. every day). More detailed information of the experiments can be found in the report [39].

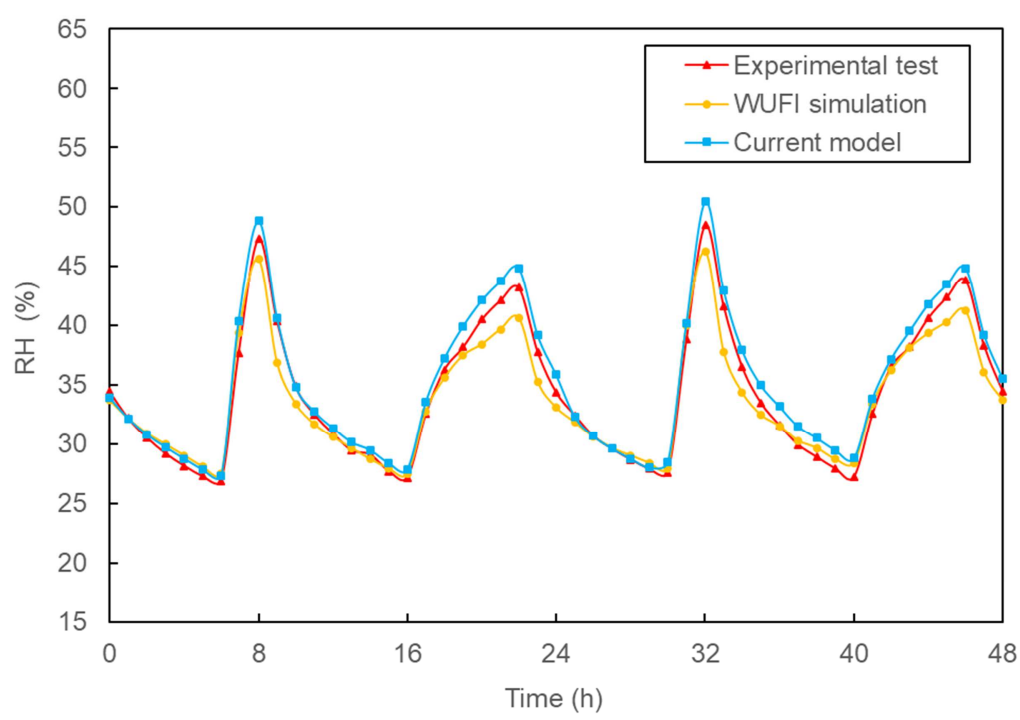

Figure 6. The comparison of simulated results from the current model and WUFI with the measured data (17 -19 Feb. 2005)

Fig.6 shows the comparison between experiment and simulations. The simulation results from WUFI is also added. The indoor temperature was treated as a constant $\left(20{ }^{\circ} \mathrm{C}\right)$ in the simulations. The calculated indoor relative humidity from the current model is slightly higher than the measured data. The mean relative error (MRE) is $2.7 \%$. Nevertheless, a considerably good agreement is found between the predicted results and the measures values. Therefore, it shows that the model is capable of simulating the indoor moisture buffering. 
Outdoor climatic conditions have a significant effect on the indoor humidity variations and the performance of porous humidity control materials. The humidity level of the outdoor air directly affect the regeneration efficiency of humidity control materials. In order to research the performance of the new MOF-PHCM on indoor humidity control and its energy saving potential in different climates, five typical climates/cities worldwide are selected. They are: Phoenix (hot desert climate), Salt Lake City (semi-arid climate), Madrid (moderate Mediterranean climate), Paris (temperate climate) and Shanghai (humid subtropical climate). These five climates cover the most populous areas in the world.

\subsection{Test building}

The BESTEST base case building from the IEA ECBCS Annex 21 [40] and Annex 41 [41] is selected as the test building. It is an $8 \mathrm{~m} \times 6 \mathrm{~m} \times 2.7 \mathrm{~m}$ single zone room (see Fig. 7 ). The current study only uses the characteristics of the BESTEST case in terms of volume and surface area to calculate the moisture buffering effect of interior porous materials on the indoor humidity variation and the latent heat load. There are no windows on the wall. The building is assumed to be a normal office room, which is only occupied from 9:00 am to 5:00 $\mathrm{pm}$. The internal moisture gain during the occupied period is $5 \mathrm{~g} \mathrm{~m}^{-3} \mathrm{~h}^{-1}$. There is no internal moisture gain during the unoccupied period. The building has a ventilation rate of $0.5 \mathrm{ACH}$ throughout the day (for the cases with night ventilation, the ventilation rate during the unoccupied period is $1 \mathrm{ACH}$ ). The sensible load and latent load are handled independently. The indoor temperature is maintained at $25{ }^{0} \mathrm{C}$ by a high temperature cooling (HTC) system $[6,42]$ during the occupied period. The HTC system uses higher temperature chilled water (e.g., $15-20^{\circ} \mathrm{C}$ ) compared to the conventional system (typical $5-7^{\circ} \mathrm{C}$ ). The HTC system only handles the sensible load, and the latent load will be handled by independent dehumidification system. Since the HTC system can largely raise the evaporation temperature, 
the corresponding COP is also much higher than conventional AC systems [6, 42]. There is no temperature control during the unoccupied period. The permissible max indoor relative humidity is $65 \%$. If the indoor RH is higher than $65 \%$, the latent load should be removed by an independent dehumidification system. All external surfaces are assumed to be covered with aluminum foil where no vapor diffusion/transfer are possible.

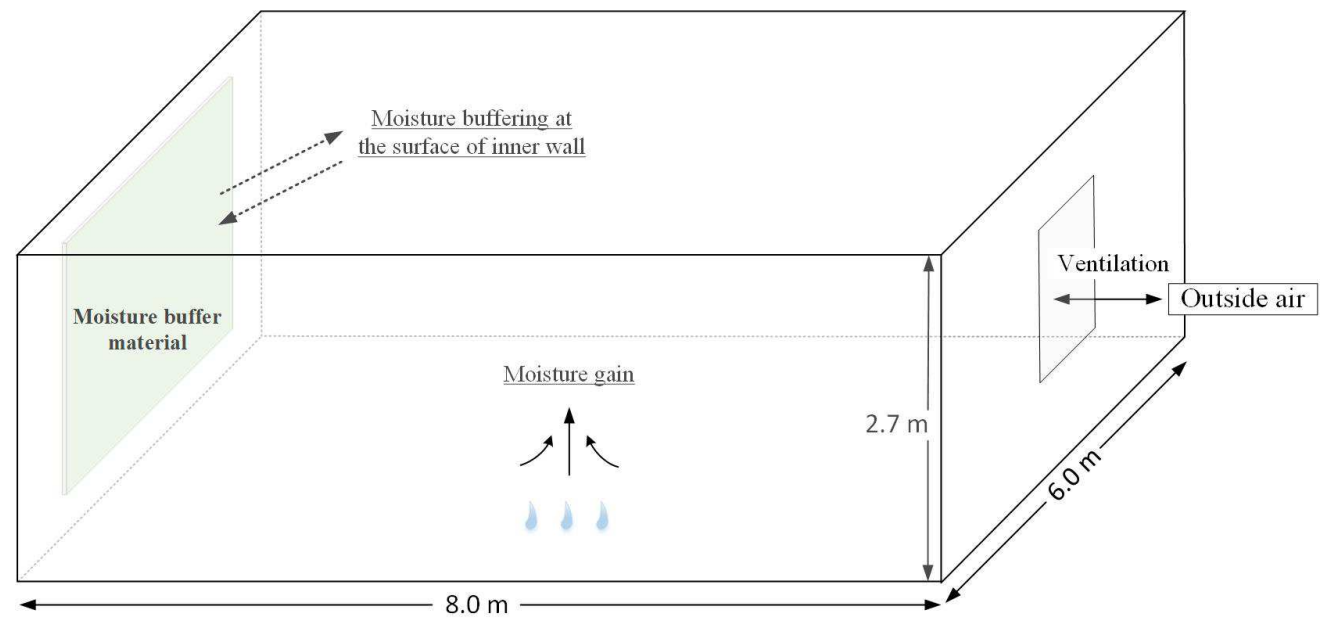

Figure 7. A single office room model.

For the cases without humidity control materials, all internal surfaces are supposed to be water-tight, and no moisture adsorption and desorption at the internal surface. For the cases with humidity control materials, an $8 \mathrm{~m}^{2}$ wall panel made by MOF-PHCM is installed on the west internal wall, which is the only moisture buffer material indoors. All other internal wall surfaces are also supposed to be water-tight. The numerical simulation aims to evaluate the performance of the MOF-PHCM panel on passive regulation of the internal humidity condition.

The program used for the simulation was written in MATLAB based on the model presented in the paper. The time-step is 1 hour. The calculations were run for as many years as it was 
necessary to achieve quasi-steady conditions. The results were reported for the last year of calculation.

\subsection{Results and discussion}

The simulation results of indoor humidity variations with and without MOF-PHCM materials in different climates are presented in this section. The corresponding energy saving potentials for latent load in different cases have also been calculated and discussed.

\subsubsection{Phoenix (hot desert climate)}

Hot desert climates are typically found under the subtropical ridge in the lower middle latitudes, often between $20^{\circ}$ and $33^{\circ}$ north and south latitude. Phoenix in the USA is one of the largest cities in this climate zone. Phoenix has hot and dry summers and mild winters. The average annual percentage of humidity is $36.0 \%$. On average, June and July are the driest months. Fig. 8 shows the indoor humidity ratio profiles for two weeks in July with and without MOF-PHCM in the Phoenix climate. The results indicate that in the case without moisture buffering materials, the indoor humidity ratio during the occupied period of the day exceeds $0.013 \mathrm{~kg} \mathrm{~kg}^{-1}\left(65 \% \mathrm{RH}\right.$ at $\left.25^{\circ} \mathrm{C}\right)$ twice a week; while in the case with MOF-PHCM, the indoor humidity ratio is all below $0.012 \mathrm{~kg} \mathrm{~kg}^{-1}\left(60 \% \mathrm{RH}\right.$ at $\left.25^{0} \mathrm{C}\right)$. No additional dehumidification is needed when MOF-PHCM is installed in the room. During the unoccupied period (the evening), the indoor humidity ratio in the case with MOF-PHCM is higher than that of the case without moisture buffer materials. The night ventilation of outside dry air $(1 \mathrm{ACH})$ can regenerate the wet MOF-PHCM. MOF-PHCM will release moisture that was adsorbed during the occupied period, and the dry MOF-PHCM will be ready for the next cycle. The simulation of the whole summer shows the indoor relative humidity of the case with MOF-PHCM varies between $60 \%$ and $35 \%$, which is perfect for indoor comfort and 
health. No additional humidity adjustment is needed in the case with MOF-PHCM in the hot desert climate.

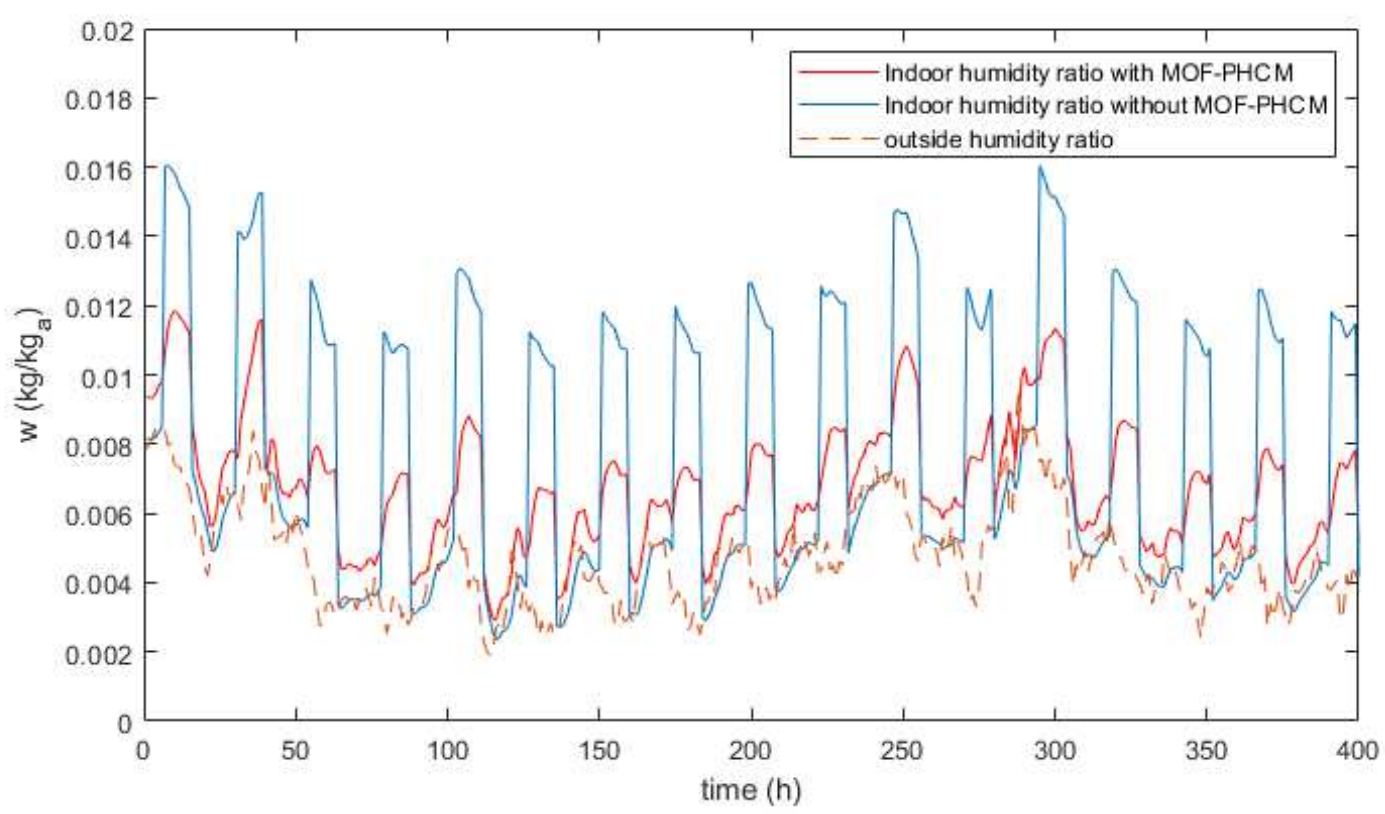

Figure 8. Simulated indoor humidity ratio (July) with and without MOF-PHCM in Phoenix

\subsubsection{Salt Lake City (hot semi-arid climate)}

Hot semi-arid climates are most commonly found around the fringes of subtropical deserts.

This climate tends to have hot summers and warm to cool winters, with some to minimal precipitation. Salt Lake City in the USA has a typical semi-arid climate. The average relative humidity in summer (June, July and August) is $33.2 \%$. The simulated indoor humidity ratio for two weeks in July with and without MOF-PHCM in Salt Lake City are presented in Fig. 9. The results indicate that in the case without moisture buffering materials, the indoor humidity ratio during the occupied period exceeds $0.013 \mathrm{~kg} \mathrm{~kg}^{-1}\left(65 \% \mathrm{RH}\right.$ at $\left.25^{0} \mathrm{C}\right)$ almost every day. Additional dehumidification is needed for this case. However, in the case with MOF-PHCM, the indoor humidity ratio reaches $0.013 \mathrm{~kg} \mathrm{~kg}^{-1}$ only one day per week. The indoor relative humidity variation with MOF-PHCM during the occupied period is between $65 \%$ and $42 \%$, which very close to the ASHRAE comfort zone. In the unoccupied period (night), the outdoor 
air with low RH could be used to dry the MOF-PHCM. The moisture released by MOF-PHCM will also be removed by night ventilation. Therefore, there is no need for extra humidity control for this case, which means MOF-PHCM could autonomously control the indoor humidity within the conform zone in semi-arid climates.

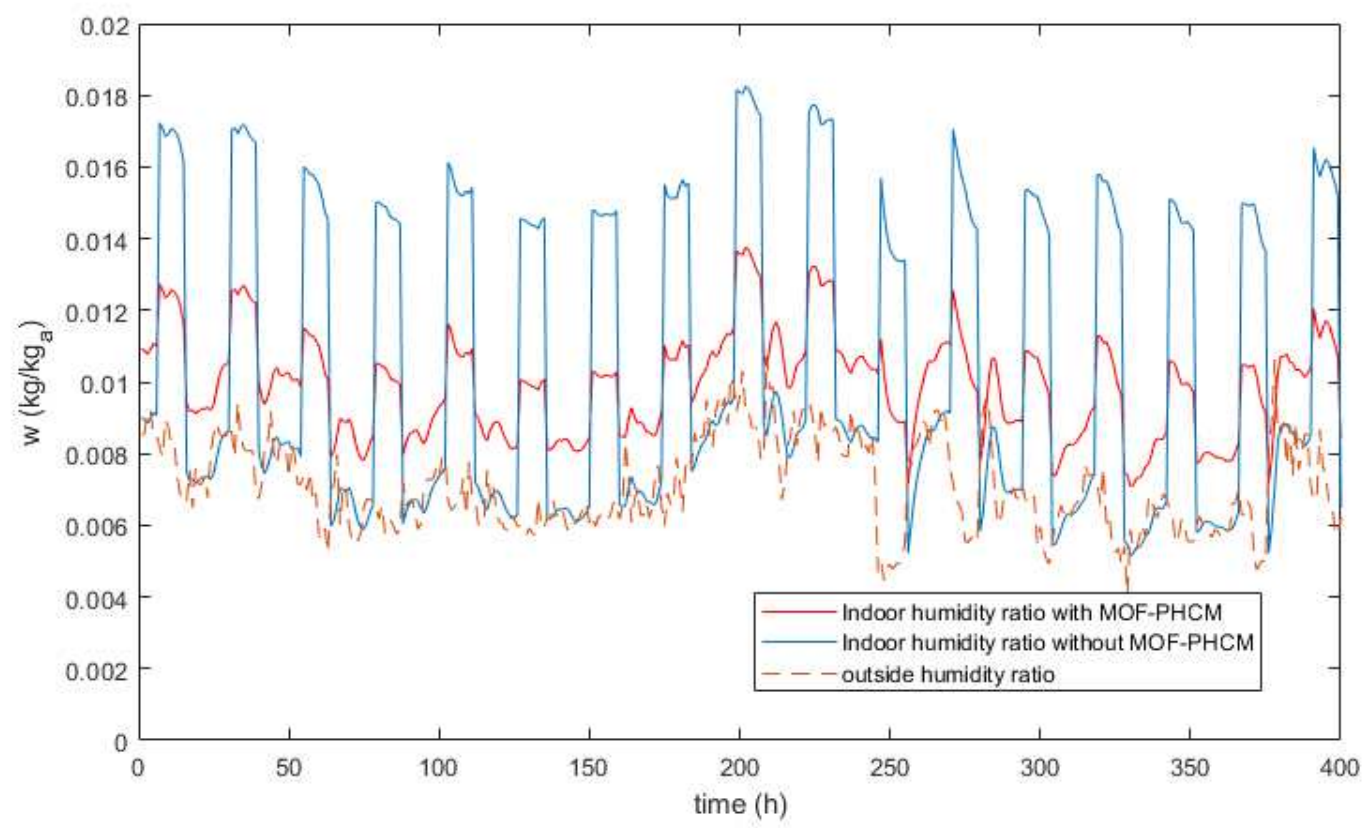

Figure 9. Simulated indoor humidity ratio (July) with and without MOF-PHCM in Salt Lake City

\subsubsection{Madrid (moderate Mediterranean climate)}

Mediterranean climate zones are typically located along the western sides of continents, between roughly $30^{\circ}$ and $45^{\circ}$ north and south of the equator. A Mediterranean climate is characterized by dry summers and mild, wet winters. Madrid in Spain has a very typical Mediterranean climate. The average outdoor relative humidity in summer is $38.2 \%$. The simulation results (see Fig. 10) show that the indoor humidity ratio without moisture buffer materials exceeds $0.017 \mathrm{~kg} \mathrm{~kg}^{-1}\left(85 \% \mathrm{RH}\right.$ at $\left.25^{\circ} \mathrm{C}\right)$ most time of the occupied period. The maximum indoor RH reaches $100 \%$ in several days. The high indoor humidity level will lead to mold formation, material deterioration and bad indoor comfort. Dehumidification is 
needed for the case without moisture buffering. In the case with MOF-PHCM, the indoor humidity ratio reaches $0.013 \mathrm{~kg} \mathrm{~kg}^{-1}$ two days per week. The indoor relative humidity with MOF-PHCM varies between $70 \%$ and $50 \%$ in the most time of the occupied period. Although it is slightly higher than the thermal comfort zone, it is still within the up limit of acceptable indoor humidity level. Very few days of high humidity will not cause mold and health problems. Therefore, there is no need for dehumidification in most days in the summer of Madrid climate with MOF-PHCM. Since the average outdoor humidity in the evening is quite low (below 40\% RH), MOF-PHCM could be regenerated by night ventilation of outdoor dry air. When most MOF-PHCM has been regenerated, the night ventilation should be stop to avoid the dry materials to start adsorb moisture in the evening. With proper control ventilation strategies, MOF-PHCM could also be used to automatous regulation of indoor air during the occupied period in the Mediterranean climates.

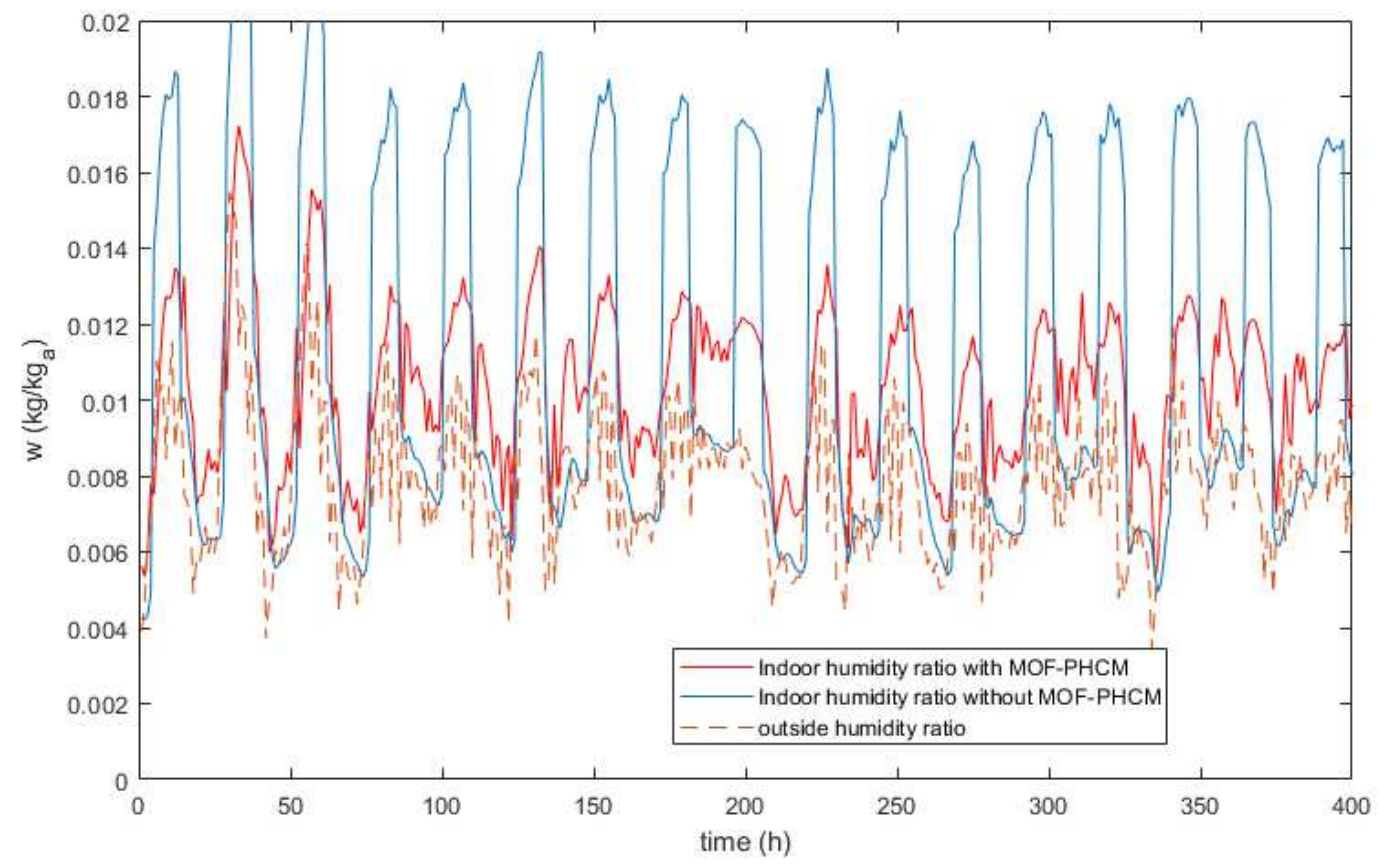

Figure 10. Simulated indoor humidity ratio (July) with and without MOF-PHCM in Madrid

\subsubsection{Paris (temperate climate)}


Paris has a temperate maritime climate, which features mild summers and mild winters, with a relatively narrow annual temperature range and few extremes of temperature. The precipitation is evenly dispersed throughout the year. It is the predominant climate type across much of Western Europe including the United Kingdom, the Pacific Northwest region of the United States and Canada etc. As to outdoor relative humidity, January is the most humid, and May is the least humid month. The average percentage of humidity in summer is around $65 \%$. The simulated indoor humidity ratio for two weeks in July in Paris is presented in Fig. 11. For the case without moisture buffering, indoor humidity during the occupied period is higher than $0.016 \mathrm{~kg} \mathrm{~kg}^{-1}\left(80 \% \mathrm{RH}\right.$ at $\left.25{ }^{\circ} \mathrm{C}\right)$ in $78 \%$ of the time. For the case with MOF-PHCM, the indoor humidity ratio reaches $0.015 \mathrm{~kg} \mathrm{~kg}^{-1}\left(75 \% \mathrm{RH}\right.$ at $\left.25^{\circ} \mathrm{C}\right)$ three to four days per week. There is a need for dehumidification for both cases. Since the outdoor air in the evening in Paris is more humid than that of the three previously discussed climates, MOF-PHCM could not be completely regenerated by night ventilation. The statistics result shows that in around half of the summer days, the outdoor humidity level in the evening meets the requirement for MOF regeneration. It means that MOF-PHCM cannot be completely regenerated in the rest half of the summer days. If the MOF-PHCM cannot be regenerated in the evening (the unoccupied period), its moisture buffer capacity will be significantly affected on the next day (the occupied period). Day 5 and 6 in Fig. 11 is an example. In these cases, additional regenerate method (e.g. heating etc.) may be needed. The detailed regeneration methods of MOF-PHCM will be discussed in the next section.

The calculation also indicates that the indoor latent load is $11.8 \mathrm{~W} \cdot \mathrm{m}^{-2}$ in Paris climate. A stand-alone MOF-PHCM wall panel regenerated by night ventilation can remove $51.5 \%$ $\left(6.08 \mathrm{~W} \cdot \mathrm{m}^{-2}\right)$ of the total latent load in the temperate Paris climate without any additional energy input. The night ventilation rate is $1 \mathrm{ACH}$. If the material is completely dried by a 
proper regeneration system (e.g. heating system powered by low-grade energy), MOF-PHCM can handle all indoor latent load.

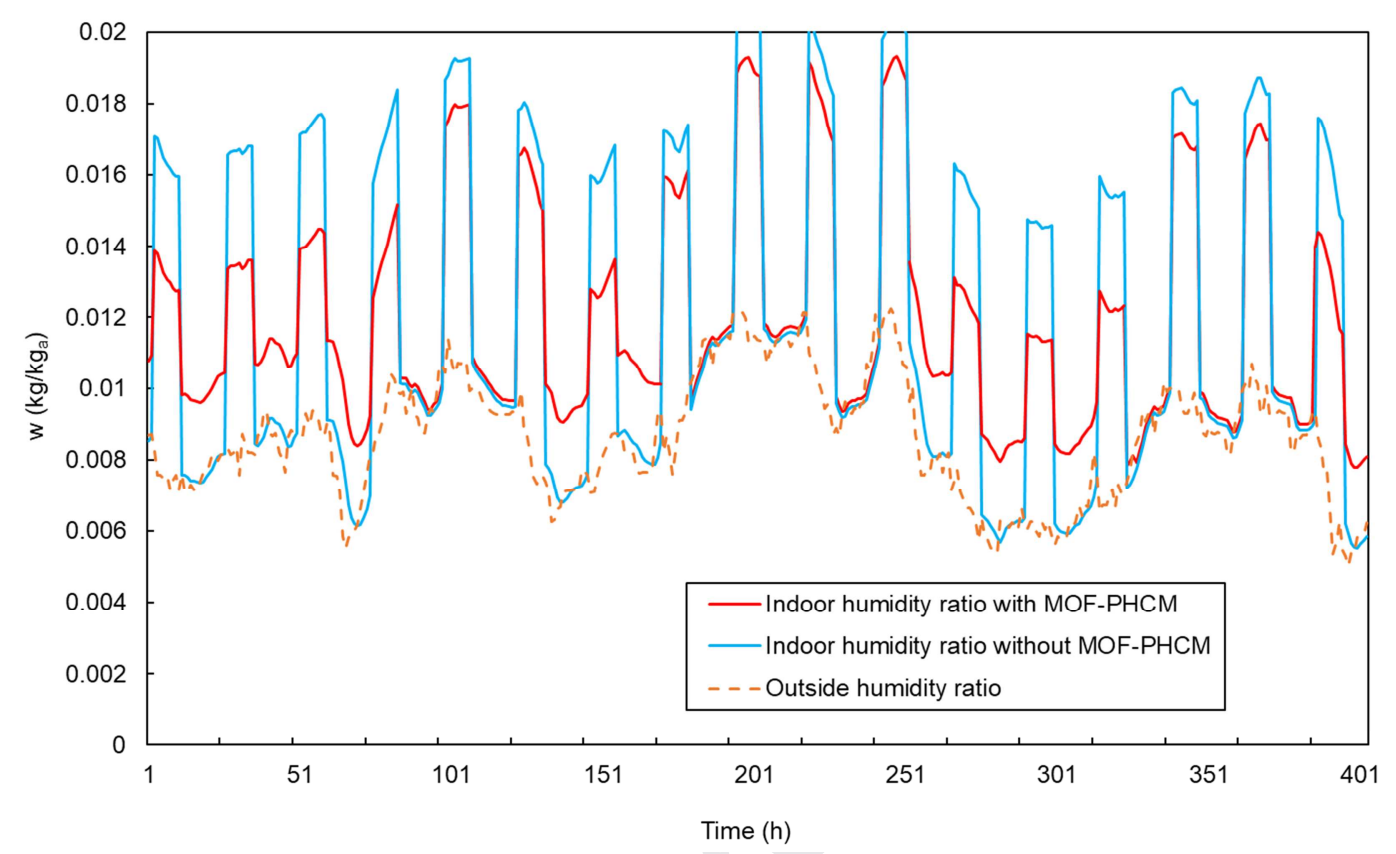

Figure 11. Simulated indoor humidity ratio (July) with and without MOF-PHCM in Paris

\subsubsection{Shanghai (humid subtropical climate)}

A humid subtropical climate is a zone of climate characterized by hot and humid summers, and cool to mild winters. Although many subtropical climates tend to be located at or near coastal locations, in some cases they extend inland, most notably in China and the United States. Shanghai has a typical humid subtropical climate. The average annual relative humidity is $80.3 \%$ and average monthly relative humidity ranges from $77 \%$ in December to $84 \%$ in June. The simulation shows that MOF-PHCM cannot work properly in this climate since the outside RH in the unoccupied period is much higher than the desorption $\mathrm{RH}$ of MOF-PHCM. Once the MOF-PHCM gets saturated, it is impossible to dry the wet MOF-PHCM purely by passive approach (e.g. night ventilation etc.)

In order to make MOF-PHCM work in the Shanghai climate, two modifications have been 
proposed: (1) double the amount of MOF-PHCM, i.e. add one more MOF wall panel on the east wall; (2) regenerate the wet MOF-PHCM by a heating system powered by low-grade energy. The heat source for the heater could be solar energy or waste heat from thermal power plants etc. Fig. 12 shows the simulated indoor humidity profiles with and without MOF-PHCM for two weeks in July in Shanghai after the improvements. The results indicate that MOF-PHCM could adsorb most moisture load in the occupied period as long as it can be completely regenerated in the following unoccupied period. In the case with MOF-PHCM, the humidity ratio is below $0.014 \mathrm{~kg} \mathrm{~kg}^{-1}\left(70 \% \mathrm{RH}\right.$ at $\left.25^{0} \mathrm{C}\right)$ most time of the week. No additional dehumidification other than MOF-PHCM is needed. If the heat for the regeneration of the material is from renewable energy or waste heat, the whole system is still very much energy efficient compared to the traditional refrigeration dehumidification. The study confirms that MOF-PHCM with a proper regeneration system can be used for passive control of the indoor humidity condition in very humid climates.

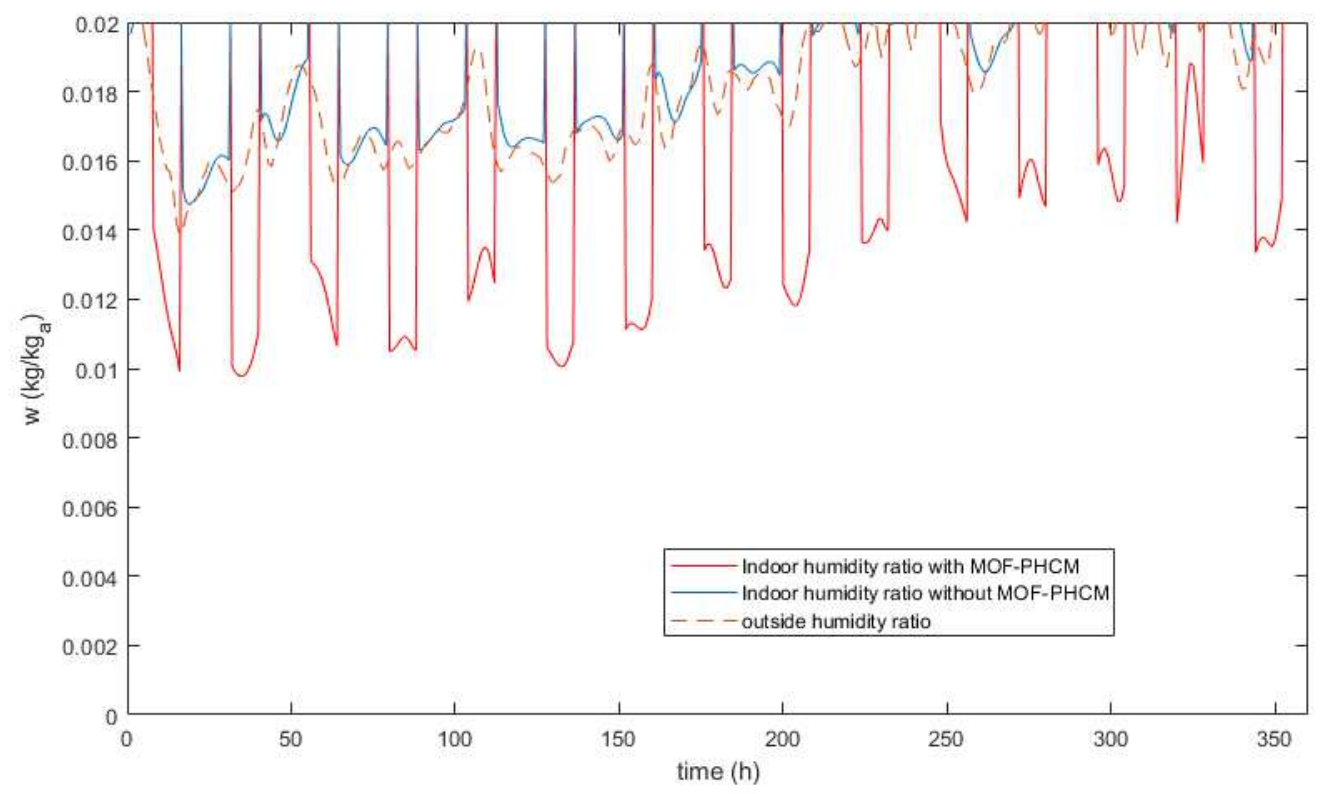

Figure 12. Simulated indoor humidity ratio (July) with and without MOF-PHCM in Shanghai

In summary, MOF-PHCM could be used for indoor moisture control in all climates. In hot 
desert climate, semi-arid climate and Mediterranean climate, MOF-PHCM could autonomously regulate indoor relative humidity within the comfort zone without any additional energy input. In temperate maritime climate, a stand-alone MOF-PHCM wall panel could remove $51.5 \%$ of the total indoor latent load without additional energy input. If the material is regenerated by a proper regeneration system, for example, heating systems powered by renewable energy, enough MOF-PHCM could also realize the autonomous control of indoor relative humidity in temperate climate. In humid subtropical climates, MOF-PHCM must be integrated with a proper regeneration system to realize the indoor humidity control. It is important to note that the amount of MOF-PHCM for moisture control in different climates should be calculated according to the indoor moisture load and outdoor weather condition.

Finally, it is necessary to mention again that the current research mainly focuses on the moisture buffer effect on the latent load of a building. We assume that the sensible load is the same for both cases with and without moisture buffer materials [36-38]. All energy-saving potentials presented in the paper refer to the latent load saving rate, and the values are evaluated based on the numerical simulation. There might be some extra energy consumption due to the night ventilation at $1 \mathrm{ACH}$ in some cases. However, take the BESTEST room as an example, the night ventilation rate at $1 \mathrm{ACH}$ is $130 \mathrm{~m}^{3} \mathrm{~h}^{-1}$. The power consumption of a fan for this ventilation rate is normally around $20 \mathrm{~W}$, which is negligible compared to the energy consumption of the air-conditioning system. In addition, the current research mainly focuses on the preparation, characterization and potential application of the new material. More detailed investigation of its integration into a specific AC system in a real building will be carried out next step. We will report the details in future papers. 


\subsection{Regeneration of MOF-PHCM}

Metal-organic frameworks (MOFs) can be regenerated either by dry air or by heating. In general, the regeneration temperature of MOFs is much lower than that of conventional sorbents or desiccants $[6,12,13]$, which makes it possible to use some low-grade energy (e.g. solar energy, waste heat from thermal power plants etc.) to regenerate it. There are many ways to regenerate the MOF-PHCM materials. The simplest way is to expose the wet MOF-PHCM to the sun, and regenerate it by using low-grade heat from natural sunlight [13]. In order to maintain a continuous operation, two MOF-PHCM panels are needed. One is in use and the other one is under regeneration by natural sunlight, and switch them every day at the beginning of the occupied period. The other simple way is to integrate the MOF-PHCM wall panel with a heater (e.g. coat the MOFs on the surface of a panel heater), and then maintain the surface temperature around $60{ }^{\circ} \mathrm{C}$ for 20-30 mins [6]. The MOF-PHCM coating will be regenerated. The heat and moisture released to the indoor space could be removed by forced ventilation, and will not significantly affect the indoor temperature. The heat source for the heater could be solar energy or waste heat from other process. Of course, this process is better completed when the room is unoccupied.

Since the energy used for regeneration is renewable, the energy efficiency of the whole MOF dehumidification system is still much higher than other normal dehumidification technologies (e.g. refrigeration, conventional solid desiccants and liquid desiccant etc.) However, due to the limitation of the paper length, a detailed description of the mechanical regeneration system for MOF-PHCM is not within the scope of this paper. We will report the system in the future studies.

\section{Conclusion}


The paper first proposes the concept of the ideal precise humidity control material (PHCM) for autonomous regulation of indoor relative humidity, and the selection criteria of PHCM. A new PHCM based on metal-organic frameworks (MOFs) has been prepared. Hygrothermal properties of the new material have been measured. This material has an S-shape isotherm, high porosity and very high water vapor uptake of $1.62 \mathrm{~g} / \mathrm{g}$ at $80 \%$ relative humidity. It can rapidly adsorb moisture as the indoor relative humidity level exceeds $60 \%$, and release moisture when the indoor relative humidity drops below $45 \%$. Compared with conventional dissidents, e.g. zeolites and silica gel etc., MOF-PHCM has high water vapor uptake capacity, lower regeneration temperature, and more importantly, MOF-PHCM can autonomously control the indoor relative humidity within the desired comfort range at room temperature.

Numerical simulations have been carried out to study the effect of MOF-PHCM on indoor hygrothermal conditions and building energy consumption in five different climates (i.e. hot desert, semi-arid, Mediterranean, temperate, and humid subtropical climates). The results show that MOF-PHCM can effectively moderate the indoor moisture fluctuation, and maintain the indoor relative humidity within the desired range in most climates as long as it can be properly regenerated. In hot desert climate, semi-arid climate and Mediterranean climate, MOF-PHCM can be regenerated by night ventilation without any additional energy input. MOF-PHCM can remove all indoor latent load passively. In temperate maritime climate, MOF-PHCM could remove up to $51.5 \%$ of the total indoor latent load by using night ventilation as the only regeneration method. Additional regeneration by heating could be used to completely dry MOF-PHCM. In humid subtropical climate, MOF-PHCM should be integrated with a proper regeneration system to realize the indoor humidity control. Since the regeneration temperature of MOF-PHCM is around $60-70{ }^{0} \mathrm{C}$, it is easy to reach that temperature by using low-grade energy (e.g. solar energy, waste heat from thermal power 
plants etc.) The whole MOF dehumidification system is zero-energy consumption as the heat for regeneration is from renewable sources.

To sum up, MOF-PHCM is a promising material for automatous regulation of indoor moisture in different climates. The MOF-PHCM synthesized in the paper focuses on the operating range of $40-65 \% \mathrm{RH}$, which is mainly for the human comfort. No refrigeration dehumidification is needed when using enough MOF-PHCM indoors. The MOF-PHCM can be easily regenerated by either night ventilation or heating system powered by renewable energy. Further studies will focus on the development of new MOF-PHCMs with different operating RH ranges for different applications and processes in industry, for example, $10-30 \%$ $\mathrm{RH}$ range for the microelectronics industry, and 20-30\% RH for the storage of artworks in the museums etc.

\section{Acknowledgements}

The authors acknowledge the support from DTU Civil Engineering and DTU Chemistry. The experiments were partially supported by the National Natural Science Foundation of China (grant no. 51578278). The authors thank Kurt Hansen and Ebba Schnell for all the support in the experiments.

\section{Reference}

[1] P. Mazzei, F. Minichiello, D. Palma, HVAC dehumidification systems for thermal comfort: a critical review, Applied Thermal Engineering, 25 (2005) 677-707.

[2] K. Chua, S. Chou, W. Yang, J. Yan, Achieving better energy-efficient air conditioning - A review of technologies and strategies, Applied Energy, 104, (2013) 87-104. 
[3] P. Mazzei, F. Minichiello, D. Palma, HVAC dehumidification systems for thermal comfort: a critical review. Applied Thermal Engineering, 25, (2005) 677-707.

[4] X. Liu, Y. Jiang, Temperature and Humidity Independent Control (THIC) of Air-conditioning System, Springer, 2013.

[5] P. K. Tsobnang, E. Hastürk, D. Fröhlich et al., Water Vapor Single-Gas Selectivity via Flexibility of Three Potential Materials for Autonomous Indoor Humidity Control, Crystal Growth \& Design 19:5, (2019) 2869-2880.

[6] S. Cui, M. Qin et al., Metal-Organic Frameworks as advanced moisture sorbents for energy-efficient high temperature cooling, Scientific Reports, Vol. 8, (2018).

[7] Lowenstein, A. Review of Liquid Desiccant Technology for HVAC Applications. HVAC\&R Res. 14, 819-839 (2008).

[8] M. Thommes, K. Kaneko, A. V. Neimark et al., Physisorption of gases, with special reference to the evaluation of surface area and pore size distribution (IUPAC Technical Report). Pure Appl. Chem. 87 (2015) 1051-1069.

[9] J. Dieckmann, Air-to-air energy recovery heat exchangers. ASHRAE J., 45, (2003) 15-16.

[10] W. Wang, L. Wu, Z. Li, Y. Fang, et al., An Overview of adsorbents in the rotary desiccant dehumidifier for air dehumidification. Drying Technol., 31, (2013) 1334-1345.

[11] G. Férey, Hybrid porous solids: past, present, future, Chem. Soc. Rev. 37 (2008) 191-214.

[12] H. Furukawa, K. Cordova, M. O’Keeffe, O. Yaghi, The Chemistry and Applications of Metal-Organic Frameworks, Science, Aug. (2013).

[13] H Kim, S Yang, S Rao, S Narayanan, A Umans, O Yaghi, and E Wang et al., Water 
harvesting from air with metal-organic frameworks powered by natural sunlight, Science, Apr (2017).

[14] X. Feng, M. Qin, S. Cui, C. Rode, Metal-Organic Framework MIL-100(Fe) as a Novel Moisture Buffer Material for Energy-Efficient Indoor Humidity Control, Building and Environment, Vol. 145, (2018).

[15] E. Ng, S. Mintova, Nanoporous materials with enhanced hydrophilicity and high water sorption capacity, Microporous and Mesoporous Materials. 114, (2008) 1-26.

[16] J. Bauer, R. Herrmann, W. Mittelbach, W. Schwieger, Zeolite/aluminum composite adsorbents for application in adsorption refrigeration, International Journal of Energy Research. 33 (2009) 1233-1249.

[17] D. Wragg, R. Johnsen, P. Norby, H. Fjellvåg, The adsorption of methanol and water on SAPO-34: in situ and ex-situ X-ray diffraction studies, Microporous and Mesoporous Materials. 134 (2010) 210-215.

[18] A. Dhakshinamoorthy, M. Alvaro, H. Garcia, Commercial metal-organic frameworks as heterogeneous catalysts, Chemical Communications. 48 (2012) 11275.

[19] F. Jeremias, D. Frolich, C. Janiak, S.K. Henninger, Advancement of sorption-based heat transformation by a metal coating of highly-stable, hydrophilic aluminum fumarate MOF. RSC Adv. 4, (2014) 24073-24082.

[20] D. Frohlich, E. Pantatosaki, P.D. Kolokathis, et al., Water adsorption behavior of CAU-10-H: a thorough investigation of its structure property relationships. J. Mater. Chem. A, 4, (2016), 11859-1869.

[21] H. Furukawa, F. Gndara, T. Zhang et al., Water adsorption in porous metal organic 
frameworks and related materials. J. Am. Chem. Soc. 136, (2014) 4369- 4381.

[22] S. Y. Zhang, S. Jensen, K. Tan et al., Modulation of water vapor sorption by a 4th generation metal-organic material with a rigid framework and self-switching pores. J. Am. Chem. Soc., 140, (2018) 12545-12552

[23] J. Ehrenmann, S. Henninger, C. Janiak et al., Water adsorption characteristics of MIL-101 for heat transformation applications of MOFs. Eur. J. Inorg. Chem. 2011, (2011) 471-474.

[24] A. Khutia, H.U. Rammelberg, T. Schmidt et al., Water sorption cycle measurements on functionalized MIL-101Cr for heat transformation application. Chem. Mater. 25, (2013) 790-798.

[25] J. Canivet, J. Bonnefoy, C. Daniel, A. Legrand et al., Structure property relationships of water adsorption in metal organic frameworks. New J. Chem. 38, (2014) 3102-3111.

[26] R. G. AbdulHalim, P. M. Bhatt, Y. Belmabkhout, A. Shkurenko et al., A fine-tuned metal organic framework for autonomous indoor moisture control. J. Am. Chem. Soc. 139, (2017) 10715-10722.

[27] P. Horcajada, S. Surble, C. Serre, D Hong et al., Synthesis and catalytic properties of MIL-100(Fe), an iron(III) carboxylate with large pores, Chemical Communications, 27, (2007).

[28] S. K. Ghosh, J. P. Zhang, S. Kitagawa, Reversible topochemical transformation of a soft crystal of a coordination polymer. Angew. Chem., Int. Ed. 46, (2007) 7965-7968.

[29] D. A. Alezi, Reticular Chemistry and Metal-Organic Frameworks: Design and Synthesis of Functional Materials for Clean Energy Applications, $\mathrm{PhD}$ thesis, King Abdullah 
University of Science and Technology, 2017.

[30] M. Zhang, M. Qin, C. Rode, Z. Chen, Moisture buffering phenomenon and its impact on building energy consumption, Applied Thermal Engineering, 124 (2017) 337-345.

[31] Z. Wu, M. Qin, M. Zhang, Phase change humidity control material and its impact on building energy consumption, Energy and Buildings, 174 (2018) 254-261.

[32] Z. Chen, D. Su, M. Qin, G. Fang, Preparation and characteristics of composite phase change material (CPCM) with $\mathrm{SiO} 2$ and diatomite as endothermal-hydroscopic material, Energy Build. 86 (2015) 1-6.

[33] C. Rode, R. Peuhkuri, B. Time, K. Svennberg, T. Ojanen et al., Moisture Buffer Value of Building Materials, Journal of ASTM International, 4 (2007) 1-12.

[34] M. Rahim, O. Douzane, A. Tran Le, G. Promis, et al., Characterization and comparison of hygric properties of rape straw concrete and hemp concrete, Construction and Building Materials, 102, (2016) 679-687.

[35] Z. Chen, M. Qin, Preparation and hygrothermal properties of composite phase change humidity control materials, Applied Thermal Engineering, 98 (2016), 1150-1157.

[36] M. Qin, R. Belarbi, F. Allard, Simulation of whole building coupled hygrothermal-airflow transfer in different climates, Energy Conversion and Management, $52(2011)$.

[37] H. Künzel, A. Holm, D. Zirkelbach, A. Karagiozis, Simulation of indoor temperature and humidity conditions including hygrothermal interactions with the building envelope, Solar Energy, 78 (2005), 554-561.

[38] M. Qin, R. Belarbi, Development of an analytical method for simultaneous heat and 
moisture transfer in building materials utilizing transfer function method, J. Mater. Civ. Eng. 17 (2005) 492-497.

[39] C. Rode, M. Woloszyn, IEA Annex 41, MOIST-ENG Subtask 1 - Modelling Principles and Common Exercises, Final report, 2007.

[40] R. Judkoff, J. Neymark, International Energy Agency building energy simulation test (BESTEST) and diagnostic method, NREL, National Renewable Energy Laboratory, Golden, 1995.

[41] C. Rode, M. Woloszyn, Common Exercises in Whole Building HAM Modelling. In C. Rode, H. Hens, \& H. Janssen (Eds.), Proceedings of the IEA ECBCS Annex 41 Closing Seminar. Copenhagen, Denmark, 2008

[42] E. Saberab, K. Thama, H. Leibundgutc, A review of high temperature cooling systems in tropical buildings, Building and Environment, 96 (2016) 237-249.

\section{Appendix A}

The isothermal cup method was used to measure the vapor transfer coefficient of the material. The saturated salt solution ( $\mathrm{NaCl}$, sodium chloride) provides a constant relative humidity $(75.3 \pm 0.12 \%$ at $25 \square)$ inside the cup. The cup was placed in a climate chamber with a constant temperature and relative humidity $(33 \pm 0.5 \% \%, 25 \pm 0.2 \square)$. Then a vapor pressure 
gradient appears across the test sample. The cup test was conducted under the conditions of a constant temperature and a given RH difference.

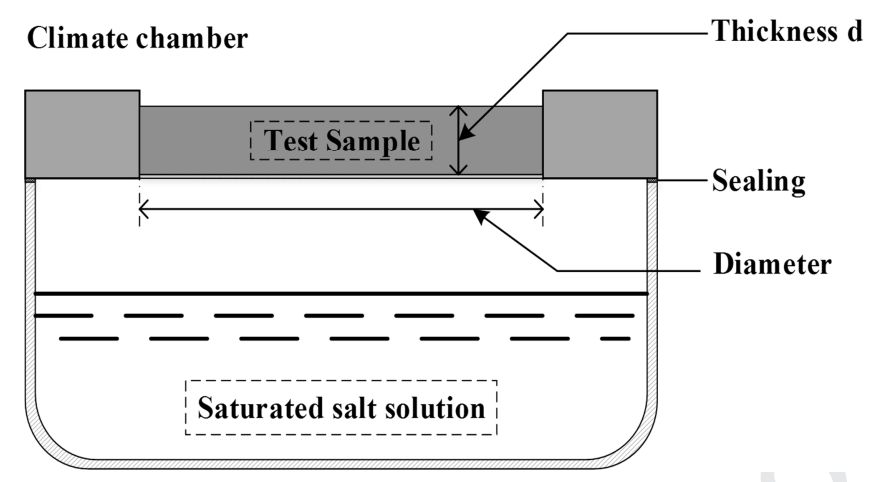

Figure A.1. Schematic of cup method

Fig. A.1 shows the schematic of the cup method test. The weight change of the cup with time was measured regularly until the mass loss reaches a steady state. The vapor transfer coefficient can be expressed as:

$$
\delta=\frac{g_{v} \cdot d}{\Delta R H}
$$

Where, $\mathrm{g}_{\mathrm{v}}$ is the moisture flow $\left(\mathrm{kg} \mathrm{s}^{-1}\right), \mathrm{d}$ is the thickness of the sample $(\mathrm{m})$, and $\Delta \mathrm{RH}$ is the difference of relative humidity on both sides of the sample. In this case, the thickness is $1.5 \mathrm{~cm}$; the diameter of the test sample is $2.5 \mathrm{~cm}$. The vapor transfer coefficient of MIL-100(Fe) can thus be calculated, and it is $1.26 \times 10^{-7} \mathrm{~kg} \mathrm{~m}^{-1} \mathrm{~s}^{-1}$. 


\section{Highlights}

- The basic concept of Precise Humidity Control Material was proposed.

- A new PHCM based on Metal-Organic Frames (MOFs) was synthesized.

- MOF-PHCM has a large water vapor uptake between $45 \%$ and $60 \%$.

- MOF-PHCM can effectively control indoor RH within the desired comfort range.

- The regeneration temperature of MOF-PHCM is around $60{ }^{\circ} \mathrm{C}$. 


\section{Declaration of interests}

$\bigotimes$ The authors declare that they have no known competing financial interests or personal relationships that could have appeared to influence the work reported in this paper.

$\square$ The authors declare the following financial interests/personal relationships which may be considered as potential competing interests: 